\title{
Mechanical Color Reading of Wood-Staining Fungal Pigment Textile Dyes: An Alternative Method for Determining Colorfastness
}

\author{
Eric M. Hinsch * and Sara C. Robinson \\ Department of Wood Science \& Engineering, Oregon State University, Corvallis, OR 97331, USA; \\ sara.robinson@oregonstate.edu \\ * Correspondence: eric.hinsch@oregonstate.edu; Tel.: +1-906-370-4773 \\ Academic Editor: Mazeyar Parvinzadeh Gashti \\ Received: 17 May 2016; Accepted: 27 June 2016; Published: 4 July 2016
}

\begin{abstract}
Colorfastness to washing and crocking (color loss due to rubbing) are essential qualities for any dye/fabric combination that will be used for garments or upholstery. In this study, colorfastness to washing and crocking of fabrics dyed with wood-staining fungal pigments was compared to colorfastness of commercial dyes using an alternative mechanical testing method. Overall, wood-staining fungal pigments out performed commercial dyes for colorfastness to washing and wet and dry crocking. Xylindein was the most colorfast dye. Draconin red yielded inconsistent results, and the yellow pigment required a mordant to achieve any colorfastness. This study showed that the mechanical color reading method, along with statistical analysis, provided an objective, repeatable gauge of colorfastness, although visual inspection is also needed for practical purposes.
\end{abstract}

Keywords: fungi; pigments; textiles; dyes; colorfastness; washing; crocking; mechanical color reading; statistical analysis

\section{Introduction}

Colorfastness to washing and crocking (color loss due to rubbing) are essential qualities for any dye/fabric combination that will be used for garments or upholstery. Once color begins to fade due to care or wear, a fabric item loses value and is often discarded. Developing colorfast fabric dyes that do not contribute more waste to an already pollutant-laden textile industry [1] is key to extending the use-life and value of fabric items, as well as reducing the environmental impact of the textile finishing industry.

Only in the last couple of years has interest surfaced in using the extracted pigments from wood-staining fungi for the direct dyeing of textiles [2,3]. Application methods for depositing the pigments onto textiles has been researched [2], as have preliminary tests for colorfastness of these pigments using the drip method of application [3]. Wood-staining fungal pigments require a relatively short amount of time and no water to dye textiles [2]. Additionally, it has been observed that these pigments demonstrate a persistence of color, both in the laboratory and after centuries of use [4-6]. These two characteristics suggest that wood-staining fungal pigments will have less of an ecological impact than commercial dyes (if used in a closed system where the solvent is recovered), which usually require heat and water, and will exhibit superior colorfastness to washing and crocking.

The current standards for testing colorfastness in the United States are the American Association of Textile Chemists and Colorists (AATCC) Evaluation Procedure 1 and Evaluation Procedure 7 [7,8]. International standards are given in the International Organization for Standarization (ISO) Textile Parts A02 and A05 [9,10]. In AATCC Evaluation Procedure 1 and ISO Textiles Part A02, colorfastness (color loss) is determined by direct visual comparison to a five- or nine-point gray scale. The problem 
presented by these evaluation methods is that visual color perception and color value judgment are highly subjective and can vary based on the experience of the observer [11]. Surface effects, including translucency and surrounding visual stimuli, can affect human visual color perception [12,13]. Additionally, both visual methods have specific lighting requirements [9], requirements which may not be possible depending on indoor lighting situations and geographical location.

In AATCC Evaluation Procedure 7 and ISO Textiles Part A05, color change is determined by digital analysis (with a colorimeter), which is correlated to the five- or nine-point gray scale. Although mechanical color reading is used, there is no mention of statistical analysis. The calculated $\Delta E^{*}$ is correlated back to the five- or nine-point gray scale. Comparison to a gray scale gives information only about perceived color value, not about hue, saturation, etc. In addition, the nine-point gray scale does not have nine different color value variations. It is identical to the five-point scale, but allows for "in-between" rankings (4-5, 3-4, etc.) [10]. Furthermore, there may be circumstances in which assessment of visually noticeable color loss is not adequate, such as using dyes to provide ultraviolet (UV) protection. A mechanical color reading (as performed on a colorimeter or spectrophotometer with International Commission on Illumination (CIE) $\mathrm{L}^{*} \mathrm{a}^{*} \mathrm{~b}^{*}$ ), in combination with statistical analysis of color changes via a $\Delta E^{*}$ output, could provide objective, repeatable results.

Based on the CIE L*a*b* color space, the human eye cannot detect a $\Delta E^{*}$ of below 2.0 [14]. A very basic level of analysis would be to find the mean $\Delta E^{*}$ of tested samples and, if the mean is lower than 2.0, consider the samples colorfast. However, there are situations where a loss of color with a $\Delta E^{*}$ below 2.0 would be undesirable. For example, if a fabric was being dyed as a means of UV protection, a statistically significant color loss could affect product performance even if the color loss could not be detected visually. A gray scale comparison using the current AATCC standards could not detect this color loss. Additionally, the AATCC Standard tests test only for a limited amount of real-life use (e.g., five home launderings, a few months of wear) $[15,16]$. Statistically significant color loss undetectable by the human eye may indicate the potential for practically significant color loss later in the life of the fabric.

The purpose of this study was to conduct a comparative analysis of colorfastness to washing and crocking on wood-staining fungal pigments (xylindein, a blue-green pigment produced by Chlorociboria aeruginosa; draconin red, a pink-red pigment produced by Scytalidium cuboideum; and an unidentified yellow pigment produced by S. ganodermophtherum) and commercial dyes, using a short-duration immersion dyeing method without heat, with both mordanted and unmordanted fabrics. Color change was assessed via mechanical color reading and statistical analysis with confirmation by visual inspection. This method of color change evaluation was chosen to eliminate subjective visual assessment and to remove reference back to a color-value only gray scale. It is hypothesized that the persistence of wood-staining fungal pigments will demonstrate greater colorfastness to washing and crocking when compared to commercial fabric dyes, and that mechanical color reading and statistical analysis will provide objective determination of color changes, some of which are not visually perceivable.

\section{Materials and Methods}

\subsection{Fabrics}

The fabrics for this study were chosen to be representative of the most common fiber genera and sub genera (Table 1). 
Table 1. Test fabrics. All fabrics are unbleached and undyed.

\begin{tabular}{ccccc}
\hline Fabric & Weight $\mathbf{( g / \mathbf { m } ^ { \mathbf { 2 } } )}$ & Threads Per Inch & Structure & Genera \\
\hline 100\% Cotton & 149 & $78 \times 76$ & Plain weave & Cellulosic seed \\
$100 \%$ Linen & 159 & $78 \times 76$ & Plain weave & Cellulosic bast \\
$100 \%$ Hemp & 254 & $34 \times 30$ & Plain weave & Cellulosic bast \\
$100 \%$ Wool & 176 & $76 \times 80$ & Plain weave & Protein \\
$100 \%$ Silk & 186 & $54 \times 54$ & Plain weave & Protein \\
$100 \%$ Rayon & 136 & $64 \times 38$ & Plain weave & Manufactured Regenerated \\
$100 \%$ Polyester & 240 & N/A & Knit & Manufactured Synthetic \\
\hline
\end{tabular}

\subsection{Fungal Pigments and Pigment Extraction}

Chlorociboria aeruginosa (strain UAMH 11657 isolated from a rotting hardwood log in Halliburton, ON, Canada), Scytalidium cuboideum (strain UAMH 11517 isolated from Quercus sp. in Memphis, TN, USA), and S. ganodermophthorum (strain UAMH 10320 isolated from oak logs used for mushroom cultivation in Gyeonggi Province, Korea) were cultured separately on sterile disposable petri plates in $2 \%$ malt agar media ( $20 \mathrm{~g}$ barley malt, $15 \mathrm{~g}$ agar, $1 \mathrm{~L}$ deionized water) mixed with approximately $2.75 \mathrm{~g}$ of sugar maple (Acer saccharum, Marshall, gather from wood turnings at Oregon State University, Corvallis, OR, USA) shavings processed through a \#20 mesh in a Wiley mill. The media was inoculated from cultures grown in $2 \%$ malt agar using the five-point inoculation technique. After inoculation, the cultures were sealed with Parafilm " $\mathrm{M}$ " and placed in drawers (separating Chlorociboria from Scytalidium) and allowed to grow at ambient room conditions $\left(21^{\circ} \mathrm{C}\right.$ and $\left.35 \% \mathrm{RH}\right)$ for two to four months based upon the growth requirements of the fungi.

Forty-eight hours prior to extraction, the Parafilm was removed from the plated cultures and the tops of the plates were removed. The opened plates were placed in a fume hood for $48 \mathrm{~h}$ to allow them to dry out. After the cultures were dry, they were broken up by hand into approximately $2 \mathrm{~cm}$ sized pieces and placed in a $250 \mathrm{~mL}$ glass round-bottomed flask. A $7.0 \mathrm{~mm} \times 24.5 \mathrm{~mm}$ octagonal magnetic stir bar was added to the flask along with $150 \mathrm{~mL}$ dichloromethane (DCM). A rubber stopper was placed on top of the flask, not inserted into it, to prevent evaporation of the DCM. The flask was then placed on a stir plate and stirred at $230 \mathrm{rpm}$ for $30 \mathrm{~min}$. After stirring, the contents of the flask were filtered through laboratory-grade Whatman No. 1002150 filter paper into a $250 \mathrm{~mL}$ glass beaker. A color reading was taken from the resultant solution on a Konica Minolta Chroma Meter CR-5 utilizing the CIE $\mathrm{L}^{*} \mathrm{a}^{*} \mathrm{~b}^{*}$ color space, on the Liquid setting. The target color readings are listed in Table 2 and represent $100 \%$ concentration of the pigments [6]. If color readings did not fall within the acceptable range, the concentration of the pigment was adjusted by either adding or evaporating off DCM as necessary. The solution was then transferred to a $1 \mathrm{~L}$ glass storage jar. This entire process was repeated until an initial $500 \mathrm{~mL}$ of pigment solution was obtained, and again to "refresh" the dye solution as needed throughout the dyeing process.

Table 2. Target color readings for fungal pigment extractions.

\begin{tabular}{ccc}
\hline Fungus & Pigment & CIE L*a*b* Target \\
\hline Chlorociboria aeruginosa & Xylindein & $\mathrm{L}^{*}=82.28, \mathrm{a}^{*}=-11.06, \mathrm{~b}^{*}=-5.40$ \\
Scytalidium cuboideum & Draconin red & $\mathrm{L}^{*}=82.32, \mathrm{a}^{*}=26.84, \mathrm{~b}^{*}=13.19$ \\
Scytalidium ganodermophthorum & Unknown & $\mathrm{L}^{*}=95.46, \mathrm{a}^{*}=-3.00, \mathrm{~b}^{*}=-8.15$ \\
\hline
\end{tabular}

\subsection{Commercial Dyes}

The dyes selected for testing are commercially available to both consumers and industry. All dyes were purchased from and manufactured by Dharma Trading Co. in Petaluma, CA, USA. Colors selected were the closest matches available to the fungal pigments (Table 3), based on visual comparison of color swatches on Dharma Trading Co.'s website. 
Table 3. Commercially available dyes used for testing.

\begin{tabular}{ccc}
\hline Dye Class & Target Fiber Type & Color \\
\hline Fiber Reactive & Cellulosic & Clear Yellow \\
Fiber Reactive & Cellulosic & Scarlet \\
Fiber Reactive & Cellulosic & Better Blue Green \\
Acid Reactive & Protein & Brilliant Yellow \\
Acid Reactive & Protein & Fire Engine Red \\
Acid Reactive & Protein & Teal Green \\
Disperse & Synthetic & Yellow \\
Disperse & Synthetic & Red \\
Disperse & Synthetic & Green \\
Natural & Cellulosic, Protein & Yellow (Osage orange) \\
Natural & Cellulosic, Protein & Red (Madder) \\
Natural & Cellulosic, Protein & Green (Spirulina) \\
\hline
\end{tabular}

To make each color of fiber reactive dye, $855 \mathrm{~mL}$ of deionized (DI) water was added to a $2000 \mathrm{~mL}$ glass beaker. Dye powder was added to $500 \mathrm{~mL}$ glass beakers in the amounts of $0.615 \mathrm{~g}$ clear yellow, $1.6 \mathrm{~g}$ scarlet, and $1.36 \mathrm{~g}$ better blue green, and mixed with enough DI water to make a paste. The DI water was increased to make $236.5 \mathrm{~mL}$ of dye slurry and stirred with a glass stirring rod. The dye slurry was then added to the $855 \mathrm{~mL}$ of DI water and stirred again. To help move the dye out of solution during the dyeing process, $66.6 \mathrm{~g}$ of non-iodized salt $(\mathrm{NaCl})$ was added to the dye solution and stirred until the salt was dissolved. To activate the dye, $5.85 \mathrm{~g}$ soda ash (purchased from Dharma Trading Co., Petaluma, CA, USA) was added to the solution and stirred until dissolved.

To make each color of acid reactive dye, $855 \mathrm{~mL}$ of DI water was added to a $2000 \mathrm{~mL}$ glass beaker. Dye powder of each color in the amount of $0.60 \mathrm{~g}$ was added to $500 \mathrm{~mL}$ glass beakers with enough hot $\left(82{ }^{\circ} \mathrm{C}\right)$ DI water to make a paste. The DI water was increased to make $236.5 \mathrm{~mL}$ of dye slurry and stirred with a glass stirring rod. The dye slurry was added to the water and stirred until well mixed. To acidify the mixture, $10 \mathrm{~mL}$ of $5 \%$ distilled white vinegar was added to the solution and stirred for $30 \mathrm{~s}$.

To make each color of disperse dye, $855 \mathrm{~mL}$ of hot $\left(82^{\circ} \mathrm{C}\right) \mathrm{DI}$ water was added to a $2000 \mathrm{~mL}$ glass beaker. Each color of dye powder in the amount of $2.33 \mathrm{~g}$ and $2.3 \mathrm{~mL}$ of color intensifier (included with each packet of dye) was added to the DI water and stirred with a glass stirring rod until the dye powder was dissolved. The beakers where then covered with aluminum foil and allowed to cool to $21^{\circ} \mathrm{C}$ overnight. The dye solutions were stirred again for $30 \mathrm{~s}$ prior to use.

For each color of natural dye, $855 \mathrm{~mL}$ of DI water was heated to $82{ }^{\circ} \mathrm{C}$ in a $5.7 \mathrm{~L}$ enameled cast iron pot. Into separate pots, $9 \mathrm{~g}$ Osage orange, $8 \mathrm{~g}$ madder, and $12 \mathrm{~g}$ spirulina were added and allowed to simmer, covered, for $1 \mathrm{~h}$. The suspensions were then filtered into $1 \mathrm{~L}$ glass mason jars through a fine mesh kitchen sieve lined with three layers of cheesecloth. The jars were sealed with canning lids and allowed to cool overnight to $21^{\circ} \mathrm{C}$. Prior to use, the dye solutions were poured into $2000 \mathrm{~mL}$ glass beakers.

\subsection{Initial Rinse Test}

Prior to cutting and dyeing, all fabrics were washed in a home washing machine in approximately $49{ }^{\circ} \mathrm{C}$ tap water and $30 \mathrm{~mL}$ of textile detergent (purchased from Dharma Trading Co., Petaluma, CA, USA) on the "regular" wash cycle. The fabrics were then tumbled dry on low for 45 min. For initial (rinse) testing, five replicates of each fabric/dye/color combination were dyed using the short-duration immersion method without heat. Seventy-five specimens of each fabric measuring $76.2 \mathrm{~mm} \times 101.6 \mathrm{~mm}$, with the warp parallel to the long dimension, were cut. For each dye type, 15 fabric specimens were placed in 3, $2000 \mathrm{~mL}$ glass beakers, 5 specimens per beaker, containing $500 \mathrm{~mL}$ of $21^{\circ} \mathrm{C} \mathrm{DI}$ water and stirred with a glass stirring rod for $30 \mathrm{~s}$ to assure thorough wetting and immersion. The specimens were allowed to soak for $15 \mathrm{~min}$. Specimens to be dyed with fungal pigments were not pre-wet as DCM is immiscible in water. 
The specimens were then removed from the DI water with stainless steel forceps and placed in $2000 \mathrm{~mL}$ beakers containing dye solution, five specimens per color. Each dye bath was stirred with a glass stirring rod for $30 \mathrm{~s}$ to assure thorough wetting and immersion. The specimens were allowed to soak for $15 \mathrm{~min}$. The specimens were then removed from the dye solution with stainless steel forceps and placed under a canopy fume hood on a drying rack constructed from standard aluminum window screening. The specimens were allowed to dry for $48 \mathrm{~h}$ at $21^{\circ} \mathrm{C}$, after which they were color read on a Konica Minolta Chroma Meter CR-5 utilizing the CIE L*a*b* color space, on the Reflectance setting with a $30 \mathrm{~mm}$ aperture. All 5 replicates of each fabric/dye/color combination were then scanned on an Epson Perfection V370 Photo color scanner. After being color read and scanned, the specimens were rinsed by immersing them in $1 \mathrm{~L}$ of $21^{\circ} \mathrm{C}$ DI water and agitating moderately with stainless steel forceps for $60 \mathrm{~s}$. This process was repeated until the rinse water remained clear. The specimens were again transferred to the drying rack and allowed to dry for $48 \mathrm{~h}$, after which they were again color read. A three-way ANOVA and Tukey HSD were run on the $\Delta E^{*}$ of the pre-rinsed and rinsed specimens for each fabric type. The fabric/dye/color combinations that were statistically colorfast (the $\Delta E^{*}$ was not statistically different) were used for the colorfastness to washing and crocking tests.

The fabric specimens for the washing and crocking tests were then dyed in a similar manner. The specimens were soaked in DI water for $15 \mathrm{~min}$-with the exception of those to be dyed with fungal pigments-then dyed for $15 \mathrm{~min}$, as above. After dyeing, however, the specimens were immediately rinsed, as described above, and allowed to dry for $48 \mathrm{~h}$ at $21^{\circ} \mathrm{C}$ before being color read. The specimens dyed with fungal pigments for these tests were not rinsed as fungal pigments do not require rinsing, and DCM is immiscible in water.

\subsection{Colorfastness to Washing}

AATCC Test Method 61-2013, Colorfastness to Laundering: Accelerated was used to test for colorfastness to washing. For each fabric/dye/color combination that passed the colorfastness to rinsing test, 5 specimens were cut, each $50.8 \mathrm{~mm}$ wide by $101.6 \mathrm{~mm}$ long with the warp in the direction of the long dimension, maintaining a $2.54 \mathrm{~cm}$ margin from each selvedge and each end of the fabric. The specimens were placed in separate Safeway brand $1 \mathrm{~L}$ plastic resealable bags (baggies) for each fabric. For each fabric/dye/color combination to be tested, 5 specimens were randomly selected from the baggies and dyed in the method outlined above for washing testing.

For each specimen to be tested, 50,3 mm stainless steel balls were added to a Type I $500 \mathrm{~mL}$ lever-lock stainless steel canister. The specimen was added to the canister. $150 \mathrm{~mL}$ of $15 \%$ (by volume) AATCC standard detergent solution (without optical brighteners) was added to the canister. The lids of the canisters were clamped and the canisters were loaded into an Atlas Launder-O-Meter Model LEF filled with hot $\left(49^{\circ} \mathrm{C}\right)$ tap water. The heater of the Launder-O-Meter was set to $49^{\circ} \mathrm{C}$ and the cycle was run for $45 \mathrm{~min}$. The canisters were removed from the Launder-O-Meter and the specimens were removed from the canisters and rinsed under running warm water until the water ran clear. The specimens were allowed to dry at $21^{\circ} \mathrm{C}$ for $48 \mathrm{~h}$ before being color read.

\subsection{Colorfastness to Crocking}

AATCC Test Method 8-2013, Colorfastness to Crocking was used to test for colorfastness to crocking. For each fabric/dye/color combination that passed the colorfastness to rinsing test, 10 specimens were cut on the bias, each $50.8 \mathrm{~mm}$ wide by $127 \mathrm{~mm}$ long, maintaining a $2.54 \mathrm{~cm}$ margin from each selvedge and each end of the fabric. The specimens were placed in separate baggies for each fabric. For each fabric/dye/color combination to be tested, 10 specimens were randomly selected from the baggies and dyed 5 at a time in the method outlined above for crocking testing.

For each specimen to be tested, a $50.8 \mathrm{~mm}$ square of AATCC Crockmeter Test Cloth was attached to the finger of an AATCC Crockmeter with the spring clip of the Crockmeter. The specimen was taped into place on the bed of the Crockmeter with masking tape. The Crockmeter bar was lowered so the finger rested on the specimen and 10 full turns of the crank were made at a rate of 1 turn/s. The 
specimen and test cloth were removed from the Crockmeter. Five specimens of each fabric/dye/color combination were tested in this manner. The procedure was repeated for the remaining 5 specimens of each combination, but the test cloth was first wetted by dipping it in $21^{\circ} \mathrm{C}$ DI water. The excess DI water was squeezed from the cloth and the cloth was blotted dry between two sheets of watercolor paper. The test cloth was then attached to the finger of the Crockmeter and the test proceeded as above. The specimens tested with the wet cloth were allowed to dry at $21^{\circ} \mathrm{C}$ for $48 \mathrm{~h}$, after which all specimens, wet tested and dry tested, were color read.

\subsection{Mordanting}

All of the above dyeing and testing procedures were repeated exactly with the same seven fabrics that had been mordanted. $3.8 \mathrm{~L}$ of tap water were added to an enameled iron pot. The water was heated to $82{ }^{\circ} \mathrm{C}$. To the water was added $13.45 \mathrm{~g}$ of alum and $2.6 \mathrm{~g}$ cream of tartar (both purchased from Dharma Trading Co., Petaluma, CA, USA). All of the cut samples for a single fabric were added to the mordant solution. The lid was placed on the pot and the fabric was allowed to simmer at $82{ }^{\circ} \mathrm{C}$ for $1 \mathrm{~h}$. The pot was removed from the heat and the fabric was allowed to cool to $21^{\circ} \mathrm{C}$ in solution. The fabric was then removed from the solution, rinsed in tap water, and the excess water was squeezed out. The samples were laid out on garment drying racks and allowed to dry for $48 \mathrm{~h}$ at $21^{\circ} \mathrm{C}$. Dyeing and testing proceeded as above.

\subsection{Data Analysis}

All statistical analyses were conducted using SAS version 9.4 (SAS Institute Inc., Cary, NC, USA). For all colorfastness tests, $\Delta E^{*}$ was calculated by the SpectraMagic NX CMS-S100w 2.33.0004 software used to run the Konica Minolta Chroma Meter CR-5 utilizing the CIE L*a*b* color space. The targets were undyed specimens of each fabric. For each fabric and test, a three-way ANOVA and Tukey HSD were run on the model:

$$
\Delta E *=\text { Dye } \mid \text { Color } \mid \text { Treatment }
$$

where $\Delta E^{*}$ is the overall change in color, Dye is the dye type (fiber reactive, acid reactive, disperse, natural, fungal pigment), Color is the dye color (yellow, red, or green), and Treatment is post-dyeing or post-testing. A statistical difference in $\Delta E^{*}$ between post-dyeing and post-testing indicated the fabric/dye/color combination was not colorfast to the specific test (rinsing, washing, crocking).

\section{Results}

\subsection{Rinse Test}

Of the 105 fabric/dye/color combinations for unmordanted fabrics, 30 were statistically colorfast to rinsing. Only these 30 combinations were further tested for colorfastness. Of the 105 fabric/dye/color combinations for mordanted fabrics, 38 were statistically colorfast to rinsing. Only these 38 combinations were further tested for colorfastness. $p$-values for the three-way interaction of dye $\mathrm{e}^{*}$ color treatment for all rinse tests, unmordanted and mordanted, were 0.005 or less at $\alpha=0.05$.

\subsection{Washing Test}

Of the 30 fabric/dye/color combinations for unmordanted fabrics tested with washing, 6 were colorfast: cotton/xylindein, hemp/draconin red, hemp/xylindein, linen/xylindein, polyester/xylindein, and wool/xylindein (Figure 1). 


\section{Colorfast to Washing (unmordanted)}

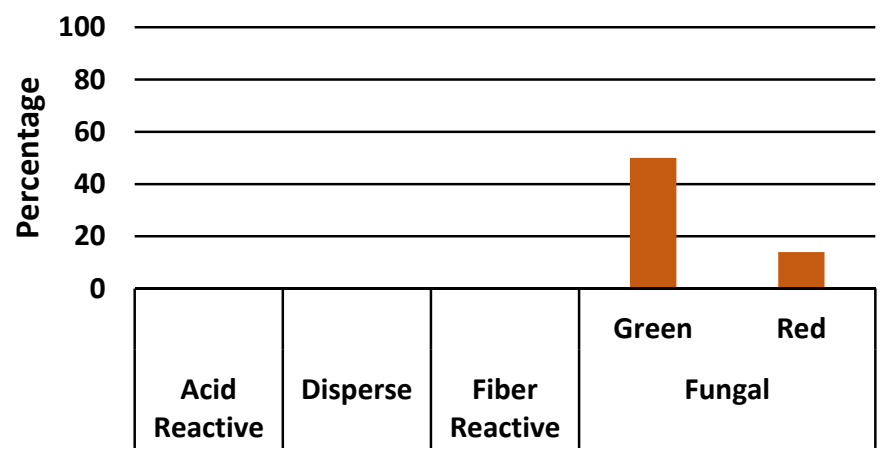

Figure 1. Results for colorfastness to washing, unmordanted.

Of the 38 fabric/dye/color combinations for mordanted fabrics tested with washing, 8 were colorfast: cotton/xylindein, hemp/yellow pigment, hemp/xylindein, polyester/xylindein, silk/xylindein, wool/yellow pigment, wool/xylindein, and wool/disperse/red (Figure 2).

\section{Colorfast to Washing (mordanted)}

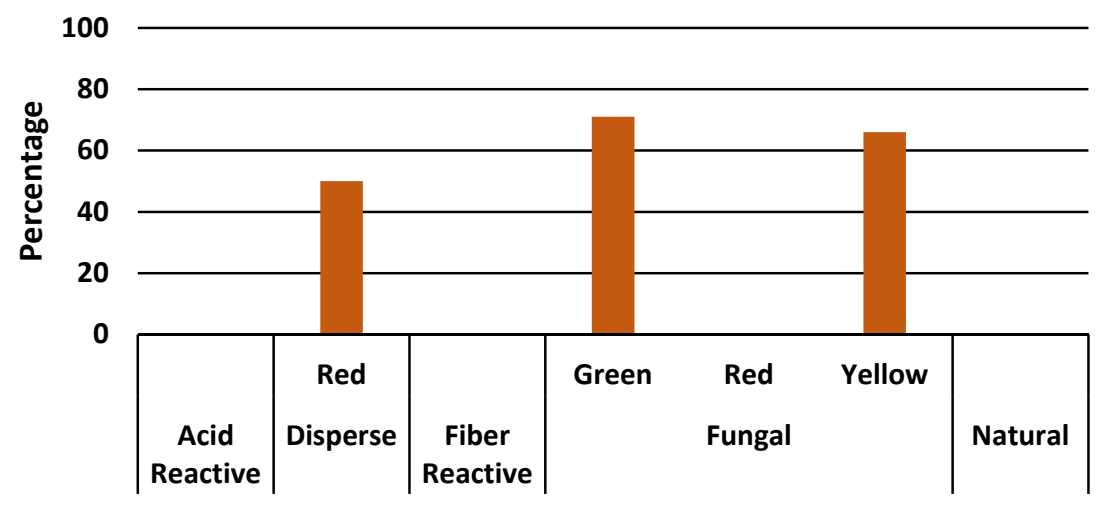

Figure 2. Results for colorfastness to washing, mordanted.

\subsection{Crocking Test}

Of the 30 fabric/dye/color combinations for unmordanted fabrics tested with dry crocking, 6 were not colorfast, and with wet crocking 9 were not colorfast (Figures 3 and 4). Half of the tested samples dyed with draconin red were not colorfast to wet crocking, and one sample dyed with xylindein (rayon) was not colorfast to wet crocking. Likewise, half of the tested samples dyed with draconin red were not colorfast to dry crocking whereas all the tested samples dyed with xylindein were colorfast. Six of seven samples dyed with fiber reactive dyes were colorfast to dry crocking and half were colorfast to wet crocking. Of the 38 fabric/dye/color combinations for mordanted fabrics tested with crocking, 16 were not colorfast to wet crocking and 19 were not colorfast to dry crocking (Figures 5 and 6). Similar to the unmordanted samples, 3 of 4 of the mordanted samples dyed with draconin red were not colorfast to wet crocking, and all samples but rayon dyed with xylindein were colorfast to wet crocking. All three mordanted tested samples dyed with the yellow pigment were colorfast to both wet and dry crocking. Over half of the mordanted samples dyed with fiber reactive dyes were colorfast to both dry and wet crocking. 


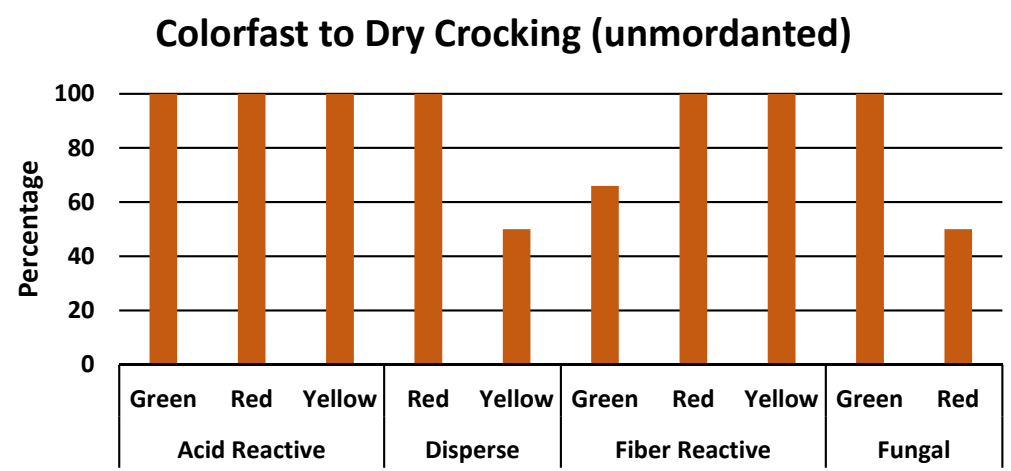

Figure 3. Results for colorfastness to dry crocking, unmordanted.

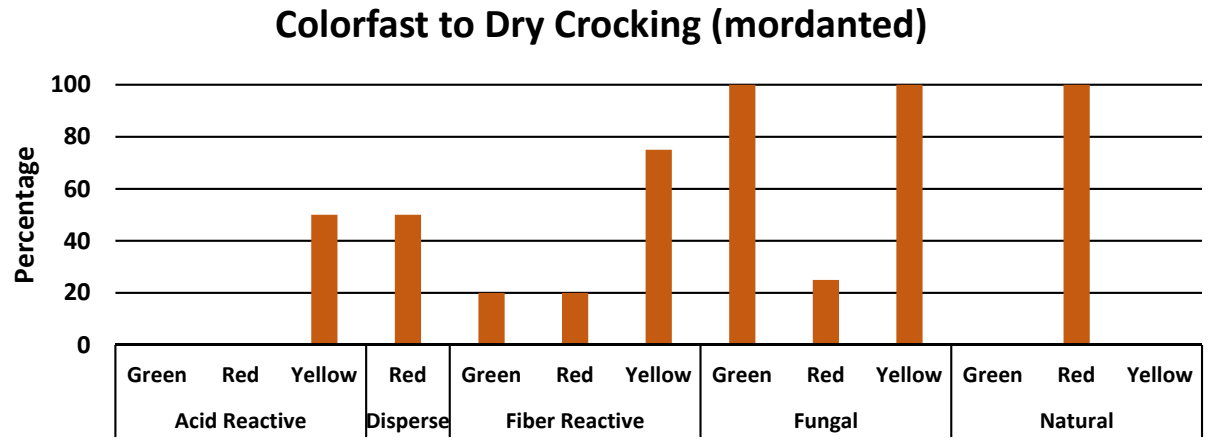

Figure 4. Results for colorfastness to dry crocking, mordanted.

\section{Colorfast to Wet Crocking (unmordanted)}

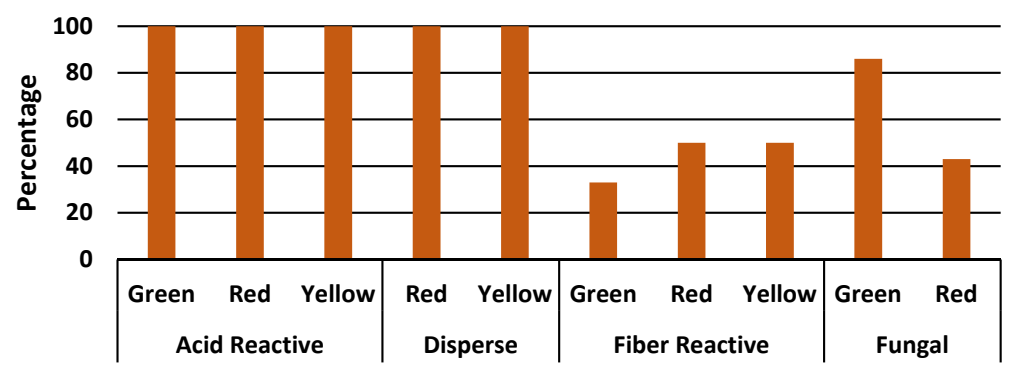

Figure 5. Results for colorfastness to wet crocking, unmordanted.

\section{Colorfast to Wet Crocking (mordanted)}

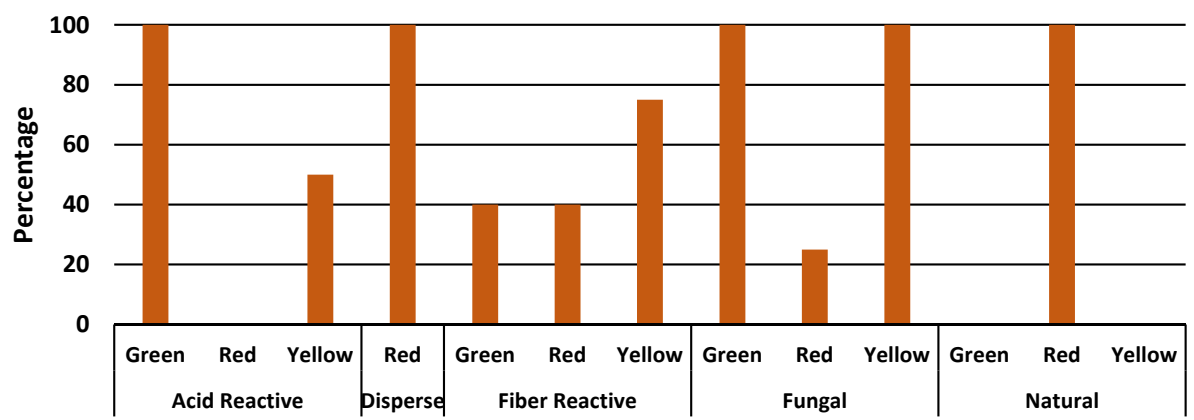

Figure 6. Results for colorfastness to wet crocking, mordanted. 


\section{Discussion}

\subsection{Colorfastness to Washing}

Only $20 \%$ of the unmordanted (cotton/xylindein, hemp/draconin red, hemp/xylindein, linen/xylindein, polyester/xylindein, and wool/xylindein) and $21 \%$ of the mordanted fabric/dye/color combinations (cotton/xylindein, hemp/yellow pigment, hemp/xylindein, polyester/xylindein, silk/xylindein, wool/yellow pigment, wool/xylindein, and wool/disperse red) were colorfast to washing. Although this may seem like a low rate of success, the washing conditions do not accurately reflect all in-home laundering conditions. For example, several of the fabrics (wool, silk, and rayon) would not be washed in hot water and would more than likely not be washed with regular laundry detergent, but rather with something milder. Future testing should include hand-washing with warm or cool water and a mild detergent as well to determine if washing method has an effect on colorfastness. This being said, fabrics dyed with xylindein were clearly more colorfast to washing than any other dye, even on fabrics that hot water will degrade, such as wool.

Several current studies, which include testing for colorfastness to washing on cotton, silk, nylon, and wool (yarn) dyed with natural dyes, demonstrated mordanting had little effect on colorfastness to washing. In a study on cotton [17], differing concentrations of two different aluminum-based mordants were tested with madder, weld, and coreopsis (Coreopsis spp.). The results showed that colorfastness to washing was very poor to poor even with increased concentrations of mordant. In contrast, cotton dyed with xylindein was colorfast to washing even without a mordant.

In a study on silk dyed with mangrove bark extract [18], mordanting did not affect colorfastness to washing, the results being very poor to poor for unmordanted and mordanted silk. In contrast, mordanted silk dyed with xylindein demonstrated colorfastness to washing whereas unmordanted silk dyed with xylindein was not colorfast to washing. Based on a comparison with the results of these two studies, xylindein performs better with regards to colorfastness to washing than some natural dyes, even when mordants are used. This could indicate xylindein's greater affinity to adhere to cotton and silk fibers than to either natural extracts or mordants.

Although nylon (polyamide) was not tested in the current study, it is a manufactured synthetic fiber and may be compared to polyester. In a study on nylon dyed with weld and pomegranate peel [19], mordanting did increase colorfastness to washing. In the current study, polyester dyed with xylindein was colorfast to washing both with and without a mordant, again demonstrating xylindein's superior colorfastness.

\subsection{Colorfastness to Crocking}

There were two samples of mordanted fabrics that were colorfast to wet crocking, but not to dry crocking: linen/disperse/yellow and polyester/draconin red. This is not a result one would expect as the wetted test cloth increases friction (as can be observed when conducting the test) and adds a potential for dissolving some of the dye on the samples. With the linen/disperse/yellow, the difference mean $\Delta E^{*}$ for dry crocking compared to pre-treatment was greater than that for wet crocking (1.31 compared to 1.04). However, the combined standard deviation for pre- and post-treatment dry crocking was greater than that for wet crocking (1.14 compared to 0.94$)$. The explanation may lie in the mean standard deviation for wet and dry crocking as a whole. The mean standard deviation for wet crocking was 0.46 and for dry crocking was 0.39 , enough of a difference compared to the small color changes that linen/disperse/yellow was statistically not colorfast. As the human eye can detect $\Delta E^{*}$ of 2.0 or greater, the differences are small enough to be visually insignificant.

As can be seen in Figure 7, wet crocking on polyester/draconin red resulted in an obvious color change, leaving an almost purple streak. The color change could be part of the extracted pigment, as Chidester [20] observed that the mycelium of Scytalidium cuboideum will sometimes turn tyrian blue. The color change may also have been caused by some type of interaction, such as the heat of friction combined with the polyester and pigment. 


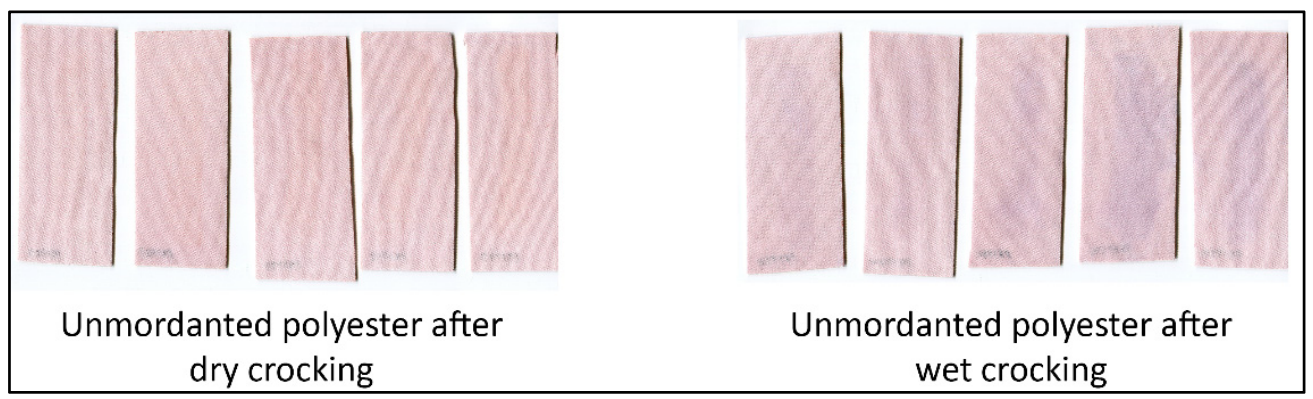

Figure 7. Unmordanted polyester dyed with draconin red shown after dry and wet crocking.

There are two possible explanations for this sample being statistically colorfast. The first, and most probable, is the more inconsistent results from wet crocking than from dry crocking, as explained above. The second is a caveat when using $\Delta E^{*}$ exclusively. The samples that were wet crocked got lighter $\left(+\mathrm{L}^{*}\right)$ and bluer $\left(-\mathrm{b}^{*}\right)$, which may account for the smaller mean $\Delta E^{*}$ for wet than for dry crocking (8.08 compared to 9.25$)$.

Several mordanted samples of both rayon and silk were statistically colorfast to wet crocking but not to dry crocking. With rayon, the two samples that exhibited this characteristic were dyed with fiber reactive red and fiber reactive green. The only other dye/color combination tested for rayon was xylindein, which was statistically colorfast to both wet and dry crocking.

The difference in mean $\Delta E^{*}$ between pre- and post-dry crocking for rayon/disperse/red and rayon/disperse green was three times that of rayon/xylindein, and seven times greater for wet crocking. The difference was statistically significant. As stated before, the difference is visually insignificant, being less than 2.0.

The three silk samples that were statistically colorfast to wet crocking but not to dry were acid reactive/green, disperse/red, and draconin red. These results are most likely due a combination of the reasons explained above for unmordanted polyester dyed with draconin red, i.e., balancing changes in parameters of $\Delta E^{*}$ and more inconsistency as a result of wet crocking. As seen in Figure 8, wet crocking on mordanted silk dyed with draconin red resulted in a darker, redder fabric. The average mean $\Delta E^{*}$ for dry crocking on mordanted silk was 19.03 and for wet crocking was 17.97 and the mean standard deviations were 0.57 and 0.66 .

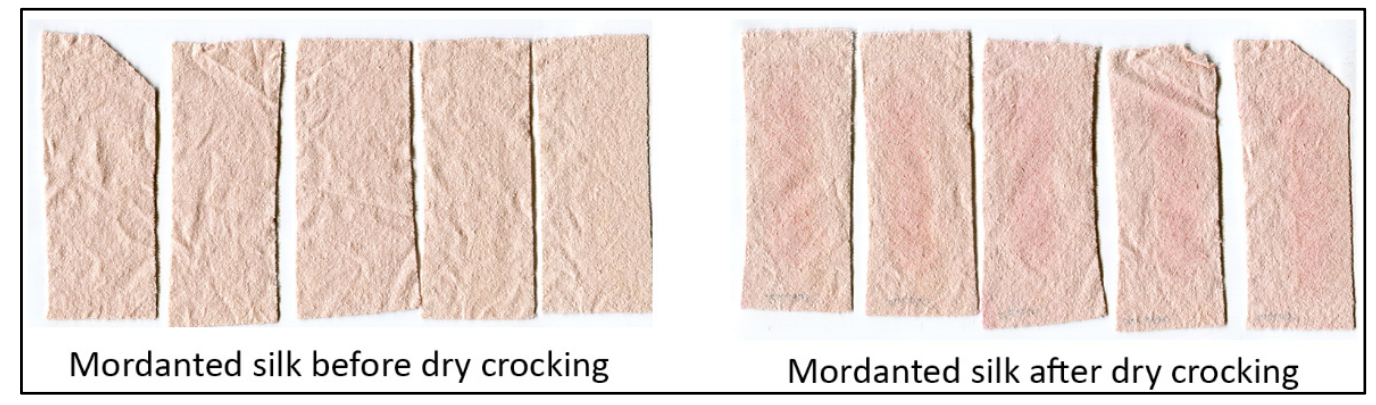

Figure 8. Mordanted silk dyed with draconin red before and after crocking.

As with washing, xylindein was the most colorfast dye to wet and dry crocking. Draconin red was disappointing and was outperformed by fiber reactive dyes in unmordanted dry crocking. The yellow pigment was, surprisingly, colorfast to crocking on mordanted fabrics, again demonstrating that mordanting appears to enhance the colorfastness of the yellow pigment.

In two current studies that included tests for colorfastness to crocking (wet and dry) on silk and nylon, mordanting had either no effect on or slightly decreased colorfastness to crocking $[18,19]$. The results of these two studies combined with the results of the current study appear to confirm that, with 
the exception of the yellow pigment, mordanting is not a successful way to improve colorfastness to crocking.

\subsection{Mechanical/Statistical Color Comparison}

Unlike AATCC and ISO standards for color loss determination, this study did not include a gray scale comparison. Visual color perception and color value judgment are highly subjective. Mechanical color reading and statistical analysis provide objective results that cannot always be detected by visual inspection. Mechanical color reading is also unaffected by surrounding visual distractions or lighting conditions, although surface effects such as streaking, wrinkling, and spotting can potentially produce misleading results. As has been demonstrated, in several cases mechanical color reading and statistical analysis revealed statistically significant color changes that would not have been detected by visual evaluation (crocking test results for linen/disperse/yellow and polyester/draconin red, and for rayon).

One caveat to using $\Delta E^{*}$ exclusively has also been demonstrated (crocking test results for unmordanted polyester/draconin red and mordanted silk/draconin red). Because $\Delta E^{*}$ is calculated from three values, two of which can be positive or negative, balanced changes in the base values could result in a $\Delta E^{*}$ s that do not show a statistically significant difference. Although mechanical and statistical color comparison may eliminate the need for visual gray scale comparison, statistical data may need to be confirmed with visual inspection when testing for colorfastness. The goal of any study of colorfastness (e.g., visual color loss, potential color loss over time, any variation in color) should dictate whether statistical significance, practical significance, or a combination of the two should be used.

\section{Conclusions}

Overall, wood-staining fungal pigments out performed commercial dyes for colorfastness to washing, and wet and dry crocking. Xylindein was the most colorfast dye. Draconin red yielded inconsistent results, and the yellow pigment required a mordant to achieve any colorfastness. With the exception of the yellow pigment and crocking, mordanting does not appear to increase the colorfastness of fungal pigments enough to warrant the time, expense, and energy necessary to mordant fabrics. Mechanical and statistical comparison of color changes yield consistent objective results as compared to the AATCC and ISO standard gray scale comparison. However, visual inspection should always be used to confirm statistical results when testing for color change. Although extracted fungal pigments show the potential to supplement commercially available textile dyes, further research is needed in the areas of consistent colorfastness and alternative dye carriers before fungal pigments can be considered a replacement for commercial dyes.

Supplementary Materials: The following are available online at http://www.mdpi.com/2079-6412/6/3/25/s1. Table S1: Tukey HSD results for unmordanted fabrics; Table S2: Tukey HSD results for mordanted fabrics.

Author Contributions: E.H. and S.R. conceived the work. E.H. designed the experiments and carried out the testing. S.R. contributed supplies and analytics help. E.H. wrote the paper and S.R. edited it.

Conflicts of Interest: The authors declare no conflict of interest.

\section{References}

1. Slater, K. Environmental Impact of Textiles: Production, Processes and Protection; Woodhead Publishing: Sawston, Cambridge, 2003; Volume 27.

2. Weber, G.; Chen, H.L.; Hinsch, E.; Freitas, S.; Robinson, S. Pigments extracted from the wood-staining fungi Chlorociboria aeruginosa, Scytalidium cuboideum, and S. ganodermophthorum show potential for use as textile dyes. Color. Technol. 2014, 130, 445-452. [CrossRef]

3. Hinsch, E.M.; Weber, G.; Chen, H.-L.; Robinson, S.C. Colorfastness of extracted wood-staining fungal pigments on fabrics: A new potential for textile dyes. J. Text. Appar. Technol. Manag. 2015, 9, 1-11. 
4. Blanchette, R.A.; Wilmering, A.M.; Baumeister, M. The use of green-stained wood caused by the fungus Chlorociboria in intarsia masterpieces from the 15th-century. Holzforschung 1992, 46, 225-232. [CrossRef]

5. Michaelsen, H.; Unger, A.; Fischer, C.-H. Blaugrüne färbung an intarsienhölzern des 16. Bis 18. Jahrhunderts: Wie kann sie identifiziert werden? Restauro 1992, 98, 17-25.

6. Robinson, S.C.; Hinsch, E.; Weber, G.; Freitas, S. Method of extraction and resolubilisation of pigments from Chlorociboria aeruginosa and Scytalidium cuboideum, two prolific spalting fungi. Color. Technol. 2014, 130, 221-225. [CrossRef]

7. Aatcc Evaluation Procedure 1: Gray Scale for Color Change; American Association of Textile Chemists and Colorists (AATCC): Durham, NC, USA, 2012.

8. Aatcc Evaluation Procedure 7-2015: Instrumental Assessment of Change in Color of a Test Specimen; American Association of Textile Chemists and Colorists (AATCC): Durham, NC, USA, 2015.

9. Textiles-Tests for Colour Fastness-Part A02: Grey Scale for Assessing Change in Colour; International Organization for Standardization (ISO): Geneva, Switzerland, 1993.

10. Textiles-Tests for Colour Fastness-Part A05: Instrumental Assessment of Change in Colour for Determination of Grey Scale Rating; International Organization for Standardization (ISO): Geneva, Switzerland, 1996.

11. Shamey, R.; Cárdenas, L.M.; Hinks, D.; Woodard, R. Comparison of naïve and expert subjects in the assessment of small color differences. J. Opt. Soc. Am. A 2010, 27, 1482-1489. [CrossRef] [PubMed]

12. Johnston, W.; Kao, E. Assessment of appearance match by visual observation and clinical colorimetry. J. Dent. Res. 1989, 68, 819-822. [CrossRef] [PubMed]

13. Steen, D.; Dupont, D. Defining a practical method of ascertaining textile color acceptability. Color Res. Appl. 2002, 27, 391-398. [CrossRef]

14. Witzel, R.; Burnham, R.; Onley, J. Threshold and suprathreshold perceptual color differences. J. Opt. Soc. Am. 1973, 63, 615-625. [CrossRef] [PubMed]

15. Aatcc Test Method 8: Colorfastness to Crocking: Crockmeter Method; American Association of Textile Chemists and Colorists (AATCC): Durham, NC, USA, 2013.

16. Aatcc Test Method 61: Colorfastness to Laundering: Accelerated; American Association of Textile Chemists and Colorists (AATCC): Durham, NC, USA, 2013.

17. Haar, S.; Schrader, E.; Gatewood, B.M. Comparison of aluminum mordants on the colorfastness of natural dyes on cotton. Cloth. Text. Res. J. 2013, 31, 97-108. [CrossRef]

18. Punrattanasin, N.; Nakpathom, M.; Somboon, B.; Narumol, N.; Rungruangkitkrai, N.; Mongkholrattanasit, R. Silk fabric dyeing with natural dye from mangrove bark (rhizophora apiculata blume) extract. Ind. Crops Prod. 2013, 49, 122-129. [CrossRef]

19. Shams-Nateri, A.; Hajipour, A.; Dehnavi, E.; Ekrami, E. Colorimetric study on polyamides dyeing with weld and pomegranate peel natural dyes. Cloth. Text. Res. J. 2014, 32, 124-135. [CrossRef]

20. Chidester, M.S. A pink stain of wood caused by a species of geotrichum. Phytopathology 1940, 30, 530-533.

(C) 2016 by the authors; licensee MDPI, Basel, Switzerland. This article is an open access article distributed under the terms and conditions of the Creative Commons Attribution (CC-BY) license (http://creativecommons.org/licenses/by/4.0/). 